\title{
Competition of Pyridoxal 5'-Phosphate with Ribulose 1,5-Bisphosphate and Effector Sugar Phosphates at the Reaction Centers of the Spinach Ribulose 1,5-Bisphosphate Carboxylase/Oxygenase
}

\author{
Joachim Vater, Thomas Gaudszun, Harald Scharnow, and Johann Salnikow \\ Max-Volmer-Institut für Physikalische Chemie und Molekularbiologie, Abteilung Biochemie, \\ Technische Universität Berlin, Franklinstr. 29, Oetkerhaus, D-1000 Berlin 10
}

Z. Naturforsch. 35 c, 416-422 (1980); received January 18/March 14, 1980

Ribulose 1,5-Bisphosphate Carboxylase/Oxygenase, Effector Studies, Pyridoxal 5'-Phosphate Inhibition

The stimulation of the carboxylase reaction by effectors of ribulose 1,5-bisphosphate carboxylase/oxygenase displays higher sensitivity towards pyridoxal 5'-phosphate inhibition than the catalytical process itself.

Pyridoxal 5'-phosphate binding to the enzyme is not affected by the modulators 6-phosphogluconate and fructose 1,6-bisphosphate at low concentrations at which these agents stimulate the carboxylation rate.

At higher concentrations these sugar phosphates protect the enzyme against pyridoxal 5'-phosphate inhibition in a similar fashion like the substrate ribulose 1,5-bisphosphate.

Such protection experiments in combination with spectrophotometrical studies of pyridoxal $5^{\prime}$ phosphate binding demonstrate two binding states of ribulose 1,5-bisphosphate at the reaction centers of the enzyme with different requirements for $\mathrm{Mg}^{2+}$. 6-Phosphogluconate functions as protector only in the presence of $\mathrm{Mg}^{2+}$.

Our results imply a competition between pyridoxal 5'-phosphate and substrate or effector sugar phosphates at the reaction centers of the spinach carboxylase. It is proposed that the pyridoxal 5'phosphate inhibition of the stimulatory activity of these effectors originates from a modification of the regulatory sites of the enzyme caused by pyridoxal 5 '-phosphate binding to the catalytical sites.

\section{Introduction}

Ribulose 1,5-bisphosphate carboxylases/oxygenases (3-phospho-D-glycerate carboxylase (dimerizing); EC 4.1.1.39) are allosteric enzymes. The activity of these enzymes can be regulated by sugar phosphates, like 6-phosphogluconate and fructose 1,6bisphosphate, which are structurally related to the substrate $\mathrm{RuP}_{2}$. Such agents stimulate the carboxylase and oxygenase reaction at low concentration and inhibit these processes at higher concentrations competitively to $\mathrm{RuP}_{2}[1-7]$.

The specific functional groups involved in effector binding as well as the mode of action of these compounds at the regulatory sites of the enzyme are still unknown. The subject of this publication is a further characterization and differentiation of the $\mathrm{RuP}_{2}$ and effector binding to the spinach carboxylase by inhibitor studies with PLP. PLP has been characterized

Abbreviations: Bicine, N,N-bis(2-hydroxyethyl)glycine; DTE, dithioerythritol; 2-ME, 2-mercaptoethanol; $\mathrm{RuP}_{2}$, ribulose 1,5-bisphosphate; PLP, pyridoxal 5'-phosphate.

Reprint requests to Dr. J. Vater.

0341-0382/80/0500-0416\$01.00/0 as an active site directed agent for reactive amino groups of $\mathrm{RuP}_{2}$ carboxylases/oxygenases [8-11].

\section{Materials and Methods}

\section{Materials}

Highly purified $\mathrm{RuP}_{2}$ carboxylase/oxygenase from spinach was prepared as described previously [7, 12].

$\mathrm{RuP}_{2}$ and the effector sugar phosphates as well as NADPH and PLP were obtained from Sigma. $\mathrm{NaH}^{14} \mathrm{CO}_{3}$ and $\mathrm{NaBT}_{4}$ were purchased from Amersham.

\section{Methods}

Binding studies with the inhibitor PLP

Spectrophotometrical measurements

The aldimine formation which occurs in the reaction of $\mathrm{RuP}_{2}$ carboxylase/oxygenase with PLP was detected spectrophotometrically. The absorption change at $432 \mathrm{~nm}$ was measured as a function of the PLP concentration similar to the procedure published by Paech et al. $[9,10]$. A Varian double beam spectrophotometer, model 635 and a Perkin-Elmer 
two wavelength spectrophotometer, model 556, was used for these measurements. The following composition of the reaction mixtures was used: $10 \mathrm{~mm}$ or $100 \mathrm{~mm}$ KOH-bicine-buffer $(\mathrm{pH}=8.0)$; $10 \mathrm{mM} \mathrm{Mg}^{2+}$; $0.25 \mathrm{~mm}$ EDTA and $1 \mathrm{~mm}$ DTE. $0.5-1 \mathrm{mg}$ of the enzyme was added to $2 \mathrm{ml}$ of this mixture. The reaction was started by the addition of PLP and run for at least 20 minutes. For the measurement of the influence of $\mathrm{RuP}_{2}$ and effector sugar phosphates on PLP binding the enzyme was preincubated with various concentrations of these agents in the presence of $10 \mathrm{mM} \mathrm{Mg}^{2+}$ or without $\mathrm{Mg}^{2+}$ prior to the addition of PLP.

\section{Fluorimetrical binding studies}

The reduced enzyme-PLP-complex was detected fluorimetrically after treatment of the aldimine with $\mathrm{NaBH}_{4}$. The composition of the reaction mixtures essentially corresponded to those applied for the spectrophotometrical experiments. For the fluorimetrical binding studies, hoẅever, lower enzyme concentrations were used $(120-150 \mu \mathrm{g}$ per $2 \mathrm{ml})$. The enzyme-PLP-complex was reduced by the addition of $\mathrm{NaBH}_{4}$ for one hour. A hundredfold excess of the reducing agent over the PLP concentration was used. After the reduction the samples were exhaustively dialyzed against $0.1 \mathrm{M} \mathrm{KOH}$-bicine-buffer $(\mathrm{pH}$ $=8.0$ ) with addition of $5 \mathrm{mM} 2$-mercaptoethanol (2-ME).

The fluorescence of the reduced enzyme-PLPcomplex was measured with a Hitachi/Perkin-Elmer MPF 4 spectrofluorimeter in ratio mode. The excitation wavelength was $328 \mathrm{~nm}$. Fluorescence emission was detected at $390 \mathrm{~nm}$, the emission maximum of the complex.

Tritium incorporation into the enzyme-PLP-complex

The reaction mixtures were the same as used for the fluorimetrical binding studies. The Schiff base formed by the enzyme with PLP was reduced with $\mathrm{NaBT}_{4}$. Thereafter the samples were exhaustively dialyzed against solutions of $50 \mathrm{~mm} \mathrm{NaCl}$ with addition of $5 \mathrm{~mm} 2-\mathrm{ME}$. After the dialysis the tritium labelled enzyme was detected by liquid scintillation spectrometry.

\section{Assays for the carboxylase activity}

Assays for the measurement of the carboxylase activity were performed essentially as described in ref. [7]. a) General assay: The reaction mixture for the determination of the carboxylase activity contained either $10 \mathrm{~mm}$ or $100 \mathrm{~mm} \mathrm{KOH}$-bicine buffer $(\mathrm{pH}=$ $8.0) ; 20 \mathrm{~mm} \mathrm{NaH}{ }^{14} \mathrm{CO}_{3}(0.1-0.5 \mu \mathrm{Ci} / \mu \mathrm{mol}) ; 20 \mathrm{~mm}$ $\mathrm{MgCl}_{2} ; 0.5 \mathrm{~mm} \mathrm{RuP} ; 0.1 \mathrm{~mm}$ EDTA and $1 \mathrm{~mm}$ DTE. The final volume was $0.5 \mathrm{ml}$. The enzyme was preincubated in the reaction mixture without $\mathrm{RuP}_{2}$ for 10 minutes at $25^{\circ} \mathrm{C}$. The reaction was initiated by the addition of $\mathrm{RuP}_{2}$ and stopped after 1 minute by acidification with $0.2 \mathrm{ml} 2 \mathrm{~N} \mathrm{HCl}$. Aliquots of the reaction mixture are dried and the acid stable products were determined by scintillation counting.

b) Assay in the presence of effectors: The enzyme was preincubated for 20 minutes in the presence of the effectors. The composition of the preincubation mixtures is specified under Legends. The bicarbonate concentration in these experiments was $0.1 \mathrm{~mm}$.

The reaction was started by the addition of either $\mathrm{RuP}_{2}$ or a mixture of $\mathrm{RuP}_{2}$ and $\mathrm{NaH}^{14} \mathrm{CO}_{3}$. The reaction time was 5 minutes at $25^{\circ} \mathrm{C}$. The samples were treated further as outlined under general assay.

\section{Protection of the $R u P_{2}$ carboxylase/oxygenase against PLP deactivation by preincubation with $R u P_{2}$ and effector sugar phosphates}

The carboxylase was preincubated in $100 \mathrm{~mm}$ $\mathrm{KOH}$ bicine-buffer $(\mathrm{pH}=8.0) ; 0.2 \mathrm{~mm}$ EDTA and $2 \mathrm{mM}$ DTE with various concentrations of $\mathrm{RuP}_{2}$ or the effector 6-phosphogluconate either in the presence of $10 \mathrm{mM} \mathrm{MgCl} 2$ or without $\mathrm{MgCl}_{2}$ for 20 minutes. Afterwards PLP was added in a concentration of $0.5 \mathrm{~mm}$ followed by a second 20 minute incubation. Finally the samples were reduced with $\mathrm{NaBH}_{4}(0.1 \mathrm{M})$ for one hour and exhaustively dialyzed against the reaction buffer. Aliquots of the reaction mixture were assayed for carboxylase activity, as described in ref. [7]. For control aliquots of the enzyme were reduced in the same way after incubation without sugar phosphate and the inhibitor PLP.

All experiments were performed at $25^{\circ} \mathrm{C}$.

\section{Results}

Binding studies were performed with PLP, as demonstrated in Fig. 1.

a) The absorption change at $432 \mathrm{~nm}$ which is characteristic for the aldimine formation between the spinach enzyme and PLP; 
Fig. 1. Double reciprocal diagram for the binding of PLP to the spinach carboxylase a) Absorption change at $432 \mathrm{~nm}(\mathrm{O})$; b) fluorescence of the reduced carboxylase-PLP-complex $(x)$ and c) tritium incorporation into the carboxylase-PLP-complex by reduction with $\mathrm{NaBT}_{4}(\triangle)$ as a function of the reciprocal PLP concentration. All data were normalized on the corresponding result at a PLP concentration of $0.05 \mathrm{mM}$. Experimental conditions as described under Methods.

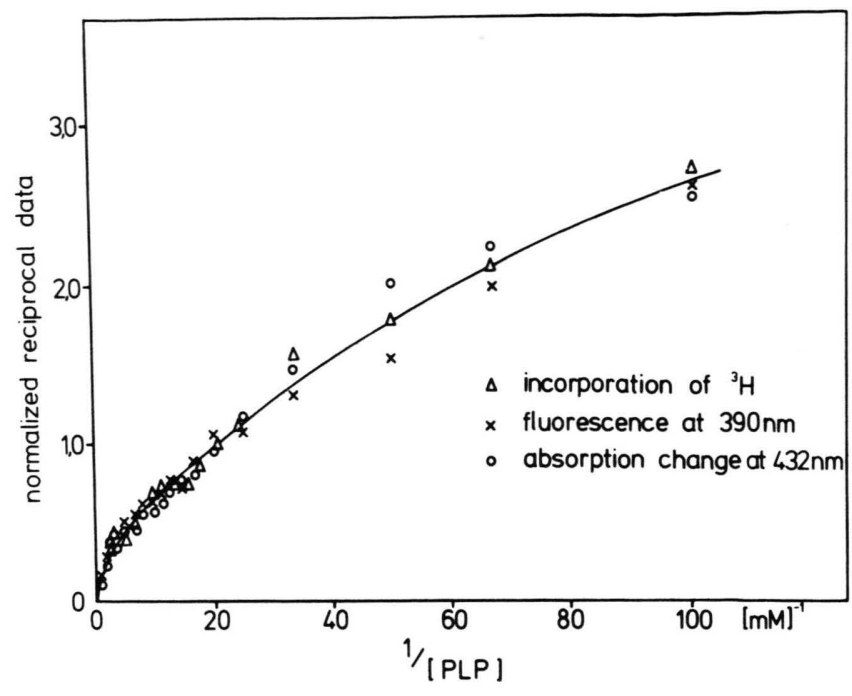

b) the fluorescence emission at $390 \mathrm{~nm}$ of the reduced carboxylase-PLP complex and

c) the tritium incorporation into this complex after the reduction of the primarily formed Schiff base with $\mathrm{NaBT}_{4}$ were determined as a measure of binding of PLP to the $\mathrm{RuP}_{2}$ carboxylase/oxygenase from spinach.

An excellent agreement of the binding patterns for all three methods was obtained. Our results essentially confirm the findings of Paech et al. [9, 10]. Assuming an extinction coefficient $\varepsilon=5800 \mathrm{M}^{-1} \mathrm{~cm}^{-1}$ for the Schiff base formation between the carboxylase and PLP published by these authors [9] we found that 1.5-2 mol of PLP were bound per functional unit $A B$ of the enzyme. From sodium dodecyl sulfate/polyacrylamide gel electrophoresis of our tritium labelled carboxylase-PLP-complexes it is apparent that $95 \%$ of the inhibitor is localized in the large subunit A of the enzyme. Only a minor incorporation (approx. 5\%) was observed in the small subunit B [13].

In Figs 2 and 3 the effect of PLP on the carboxylase activity of the spinach enzyme was studied under various reaction conditions. Fig. 2 shows the influence of $\mathrm{Mg}^{2+}$ and the effector 6-phosphogluconate on the PLP inhibition of $\mathrm{CO}_{2}$ fixation.

In the absence of the inhibitor the effector 6-phosphogluconate enhances the carboxylation rate by a factor of 3.5 , if $\mathrm{Mg}^{2+}$ is added to the preincubation mixture. The effector activity of 6-phosphogluconate, which is defined as the difference in the car- boxylation rates in the presence and absence of the effector was $250 \%$. If $\mathrm{Mg}^{2+}$ is omitted from the preincubation mixture, no stimulation of the $\mathrm{CO}_{2}$ fixation by 6-phosphogluconate is observed.

In Fig. 2 the data for each curve were normalized on the carboxylation rate measured under the different reaction conditions in the absence of PLP. It is apparent that in the presence of $10 \mathrm{mM} \mathrm{MgCl}_{2} \mathrm{CO}_{2}$ fixation is stimulated at low PLP concentrations in the range of $0.1-20 \mu \mathrm{M}$. The maximal enhancement effect was about $30 \%$ of the carboxylation rate

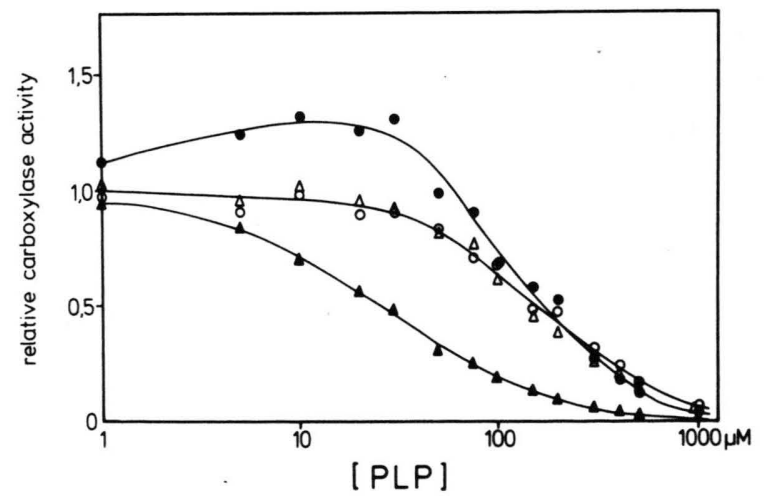

Fig. 2. Relative carboxylase activity as a function of the PLP concentration under various preincubation conditions. The spinach carboxylase was preincubated for 20 minutes in $0.1 \mathrm{M} \mathrm{KOH}$-bicine-buffer $(\mathrm{pH}=8.0) ; 0.1 \mathrm{mM}$ EDTA; $1 \mathrm{mM}$ DTE and a) with $10 \mathrm{mM} \mathrm{MgCl}_{2}(\bullet)$; b) without $\mathrm{MgCl}_{2}$ (O); c) with $10 \mathrm{~mm} \mathrm{MgCl}$ and $20 \mu \mathrm{M}$ 6-phosphogluconate $(\boldsymbol{\Delta})$ and d) with $20 \mu \mathrm{M}$ 6-phosphogluconate without $\mathrm{MgCl}_{2}(\triangle)$. Afterwards the carboxylase reaction was started by the addition of $0.5 \mathrm{mM} \mathrm{RuP}{ }_{2}$ and $0.1 \mathrm{~mm}$ $\mathrm{NaH}^{14} \mathrm{CO}_{3}$. The reaction time was 5 minutes. 


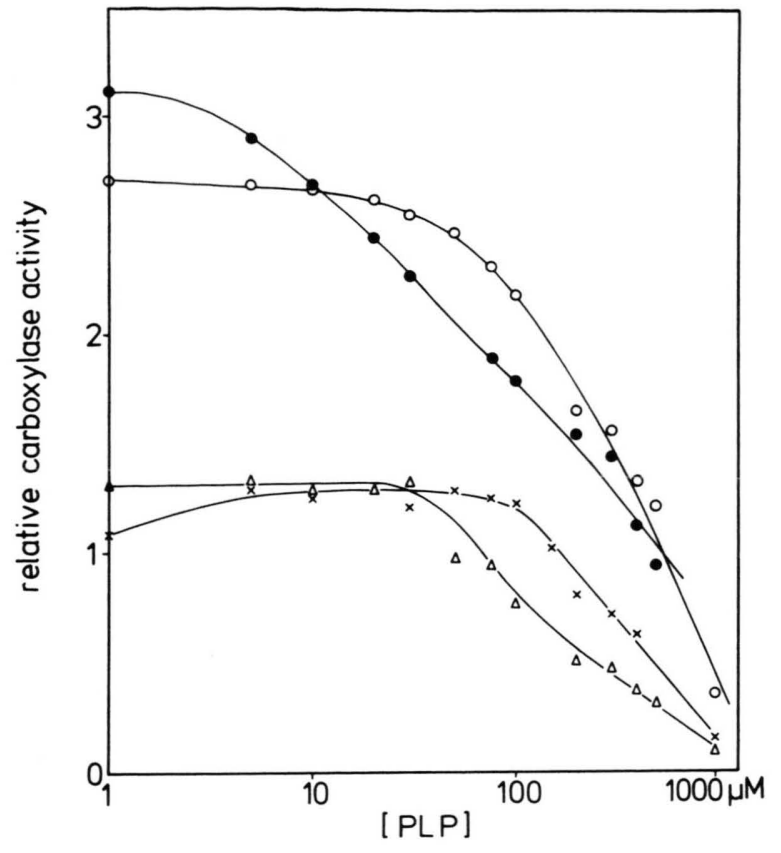

Fig. 3. Relative carboxylase activity as a function of the PLP concentration. The enzyme was preincubated for 20 minutes in $0.1 \mathrm{M} \mathrm{KOH}$-bicine-buffer $(\mathrm{pH}=8.0) ; 0.1 \mathrm{~mm}$ EDTA; $1 \mathrm{~mm}$ DTE; $10 \mathrm{~mm} \mathrm{MgCl}_{2}$ and $0.1 \mathrm{~mm} \mathrm{NaH}{ }^{14} \mathrm{CO}_{3}$ and a) without effector (x); b) with $20 \mu \mathrm{M}$ 6-phosphogluconate (O); c) with $200 \mu \mathrm{M}$ fructose 1,6-bisphosphate $(\triangle)$; d) with $1 \mathrm{~mm}$ NADPH $(O)$. The reaction was started by the addition of $0.5 \mathrm{mM} \mathrm{RuP}_{2}$. Reaction time: 5 minutes.

without PLP. Stimulation is not observed, if $\mathrm{Mg}^{2+}$ is omitted from the preincubation mixture. At higher PLP concentrations $(20 \mu \mathrm{M}-1 \mathrm{mM})$ PLP functions as an inhibitor of the carboxylase reaction both in the presence of $10 \mathrm{mM} \mathrm{Mg}^{2+}$ as well as without $\mathrm{Mg}^{2+}$. $50 \%$ inhibition is obtained at about $150 \mu \mathrm{M}$ PLP.
In the presence of $10 \mathrm{mM} \mathrm{Mg}^{2+}$ in the preincubation the PLP inhibition of the carboxylase activity is enhanced at low concentrations of the effector 6phosphogluconate $(20 \mu \mathrm{M})$. Effective inhibition occurs already at PLP concentrations below $10 \mu \mathrm{M}$ under these conditions. $50 \%$ inhibition is observed at about $25 \mu \mathrm{M}$. If $\mathrm{Mg}^{2+}$ is omitted in the preincubation no enhancement of the PLP inhibition is detectable and the same inhibition profile is obtained as without the effector.

In Fig. 3 the PLP inhibition of $\mathrm{CO}_{2}$ fixation in the presence of 6-phosphogluconate, fructose 1,6-bisphosphate and NADPH is compared with the inhibition without effector. The effector activities of these agents in the absence of PLP were $227 \%$ for 6 phosphogluconate, $38 \%$ for fructose 1,6-bisphosphate and $178 \%$ for NADPH.

In Figs 4 and 5 the effector activities of 6-phosphogluconate and fructose 1,6-bisphosphate in the carboxylase reaction have been determined in the presence of $0.5 \mathrm{mM}$ PLP and without the inhibitor. The stimulation of the carboxylase activity by these regulatory sugar phosphates is always more strongly inhibited by PLP than the catalytical process. The inhibitory effect of 6-phosphogluconate and fructose 1,6-bisphosphate on $\mathrm{CO}_{2}$ fixation is shifted to higher sugar phosphate concentrations in the presence of PLP. These measurements have been correlated to the decrease of PLP binding in the presence of these agents indicated by the absorption change at $432 \mathrm{~nm}$.

In Figs 6 and 7 the protective effect of the substrate $\mathrm{RuP}_{2}$ and the effector 6-phosphogluconate on the carboxylase activity are demonstrated. Different $\mathrm{Mg}^{2+}$ dependent protection effects have been obtained for these sugar phosphates.
Fig. 4. Relative carboxylase activity $(O$ ) and relative decrease of the absorption change of the carboxylase-PLPcomplex at $432 \mathrm{~nm}(\mathrm{x})$ as a function of the 6-phosphogluconate concentration in the preincubation medium. 1. Assays: The enzyme was preincubated for 20 minutes in $0.1 \mathrm{M} \mathrm{KOH}$-bicine-buffer $(\mathrm{pH}=8.0) ; 0.1 \mathrm{~mm}$ EDTA; $1 \mathrm{~mm}$ DTE; $10 \mathrm{mM} \mathrm{MgCl}_{2}$ and various effector concentrations. a) with $0.5 \mathrm{~mm}$ PLP (O) and $b)$ without PLP $(O)$. The reaction was started by the addition of $0.5 \mathrm{~mm}$ $\mathrm{RuP}_{2}$ and $0.1 \mathrm{~mm} \mathrm{NaH}{ }^{14} \mathrm{CO}_{3}$. 2. Spectrophotometrical measurements as indicated under Methods.

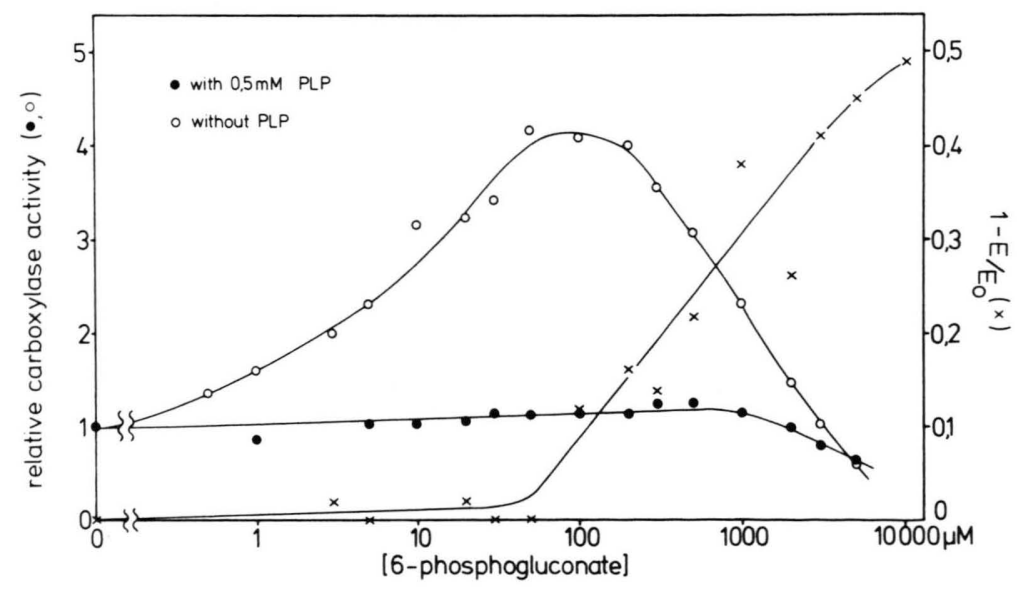




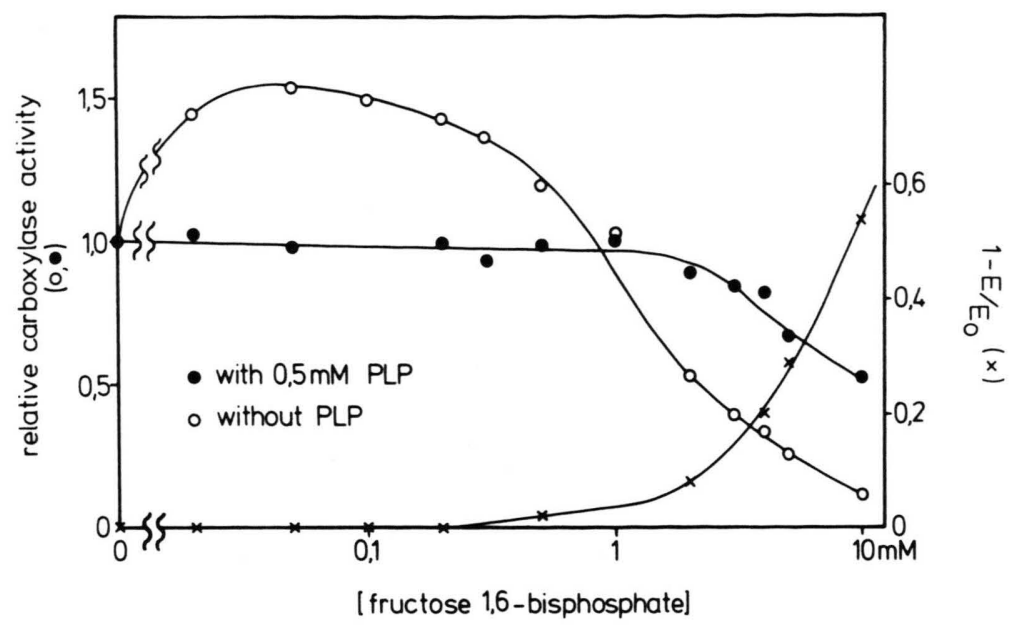

Fig. 5. Relative carboxylase activity $(O, 0)$ and relative decrease of the absorption change of the carboxylase-PLPcomplex at $432 \mathrm{~nm}(x)$ as a function of the fructose 1,6-bisphosphate concentration in the preincubation medium. Experimental conditions as described in the legend of Fig. 4.

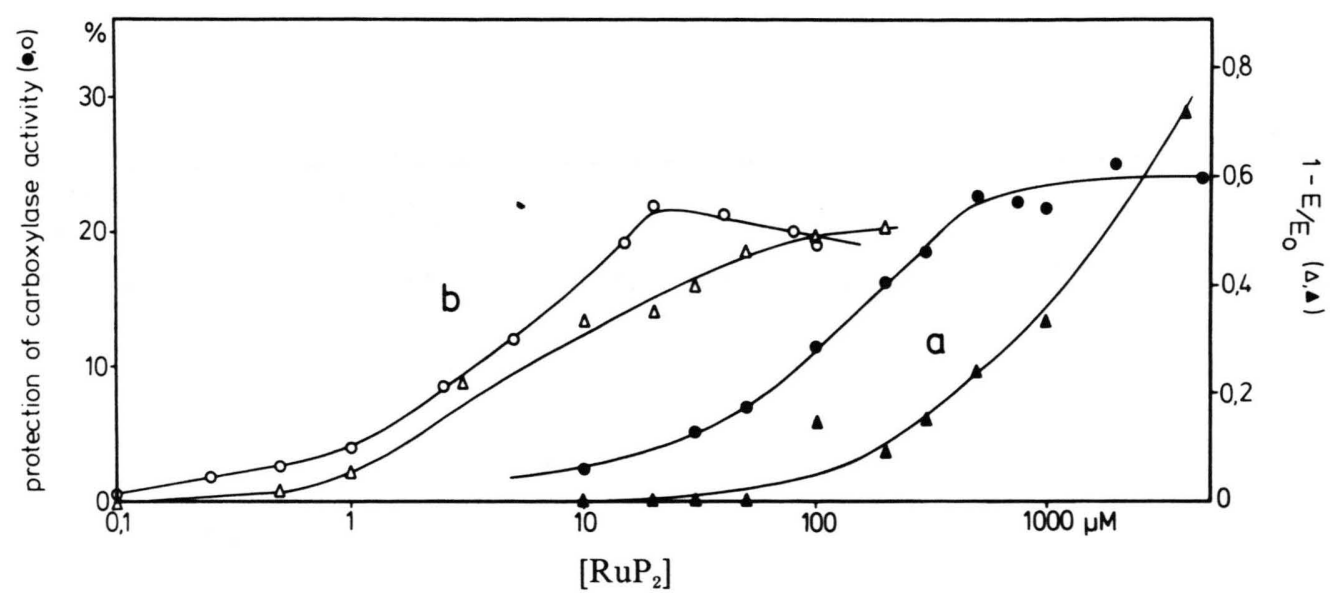

Fig. 6. Protection of the spinach carboxylase against PLP-inhibition $(O, 0)$ and relative decrease of the absorption change of the carboxylase-PLP-complex at $432 \mathrm{~nm}(\boldsymbol{\Delta}, \triangle)$ as a function of the $\mathrm{RuP}_{2}$ concentration in the preincubation medium. a) in the presence of $10 \mathrm{mM} \mathrm{MgCl}(\boldsymbol{O}, \boldsymbol{\Delta})$ and b) without $\mathrm{MgCl}_{2}(O, \Delta)$ in the preincubation mixture. Experimental conditions as indicated under Methods.

$\mathrm{RuP}_{2}$ functions as an effective protector of the carboxylase both in the presence of $10 \mathrm{mM} \mathrm{MgCl}_{2}$ and without $\mathrm{Mg}^{2+}$ in the preincubation medium. In the presence of $\mathrm{Mg}^{2+}$ protection is found in a range of $10 \mu \mathrm{M}-1 \mathrm{mM} \mathrm{RuP}{ }_{2}$, whereas in the absence of $\mathrm{Mg}^{2+}$ the protective effect of $\mathrm{RuP}_{2}$ is observed at lower concentrations between 0.5 and $10 \mu \mathrm{M}$.

Similar results have been obtained for the $\mathrm{RuP}_{2}$ induced decrease of the absorption change at $432 \mathrm{~nm}$ characteristic for the aldimine formation between reactive amino groups of the carboxylase and PLP. In the absence of $\mathrm{Mg}^{2+}$ the absorption change is reduced to maximally $45 \%$ at $\mathrm{RuP}_{2}$ concentrations between 1 and $100 \mu \mathrm{M}$, while in the presence of $10 \mathrm{mM} \mathrm{Mg}^{2+}$ a decrease of more than $80 \%$ was found in a concentration range of $0.05-4 \mathrm{mM} \mathrm{RuP}_{2}$. Different carboxylase preparations were used for the protection studies and the spectrophotometrical measurements. A lower PLP concentration $(100 \mu \mathrm{M})$ was used in the optical measurements than in the 


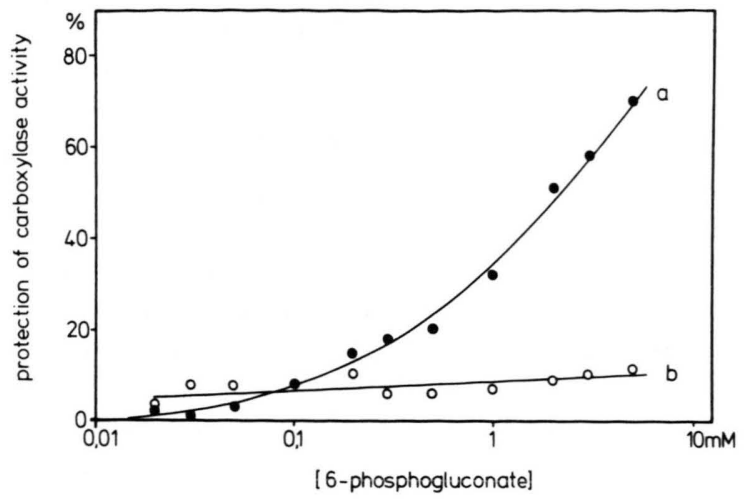

Fig. 7. Protection of the spinach carboxylase against PLPinhibition by preincubation with 6-phosphogluconate. a) in the presence of $10 \mathrm{mM} \mathrm{MgCl}_{2}(-)$ and b) without $\mathrm{MgCl}_{2}$ (O) in the preincubation mixture. Experimental conditions as indicated under Methods.

protection experiments $(500 \mu \mathrm{M})$ for instrumental reasons.

In contrast to the substrate $\mathrm{RuP}_{2}$ the effector 6phosphogluconate shows a significant protection of the carboxylase reaction against PLP inhibition only in the presence of $\mathrm{Mg}^{2+}$.

\section{Discussion}

In this publication the action of PLP on the carboxylase reaction was studied under various reaction conditions. The special interest in this work was to detect differences in the mode of binding of $\mathrm{RuP}_{2}$ and effector sugar phosphates, like 6-phosphogluconate and fructose 1,6-bisphosphate, at the catalytical and regulatory centers of the $\mathrm{RuP}_{2}$ carboxylase/oxygenase from spinach.

PLP inhibits both the carboxylase and the oxygenase reaction [9] and has been reported as an active site directed agent for reactive amino groups of $\mathrm{RuP}_{2}$ carboxylases/oxygenases [9-11].

Inhibitor studies with PLP under various reaction conditions are shown in Figs 2-5. From Fig. 2 it is apparent that PLP inhibition of the carboxylase is markedly enhanced by the effector 6-phosphogluconate only in the presence of $\mathrm{Mg}^{2+}$, consistent with the $\mathrm{Mg}^{2+}$ requirement of the effector binding [7, 12]. A conformational change of the enzyme is induced under these conditions, as detected fluorimetrically $[7,12]$ which obviously causes a tighter binding of the inhibitor PLP.
Whitman et al. [11] observed an analogous enhancement effect by activation of the Rhodospirillum rubrum enzyme with $\mathrm{Mg}^{2+}$ and bicarbonate. Similar results we have obtained also for the spinach enzyme under these conditions (data not shown). From these experiments it follows that PLP inhibition of the carboxylase reaction is most effective, if the enzyme is in an activated state which can be achieved either by bicarbonate or effector activation of the carboxylase in the presence of $\mathrm{Mg}^{2+}$. PLP binding therefore can be taken as an indicator for the activation state of the enzyme.

Whitman et al. [14] have shown that PLP also functions as an effector of the carboxylase reaction at low PLP concentrations. Our experiments confirm their results, as it is apparent from Figs 2 and 3. In contrast to these authors, however, we find a $\mathrm{Mg}^{2+}$ requirement for this effect similar to the effector activity of the regulatory sugar phosphates 6-phosphogluconate and fructose 1,6-bisphosphate.

The effect of PLP on the activity of these agents relating to $\mathrm{CO}_{2}$ fixation was investigated in Figs 3-5 and compared to the action of these compounds on PLP binding. The stimulation of the carboxylase reaction induced by these effectors is inhibited by PLP at lower concentrations than the catalytical process. This effect is most pronounced for 6-phosphogluconate. For example, the effector activities of 6phosphogluconate and fructose 1,6-bisphosphate are completely abolished at a PLP concentration of $0.5 \mathrm{mM}$, whereas $\mathrm{CO}_{2}$ fixation still functions at an appreciable extent $(30-40 \%)$.

This result could be interpreted as the consequence of a competition between the effectors and $\mathrm{PLP}$ at the regulatory sites of the $\mathrm{RuP}_{2}$ carboxylase/ oxygenase. Under these conditions one should expect a decrease of PLP binding with increasing effector concentration in the range, where 6-phosphogluconate and fructose 1,6-bisphosphate express their stimulating effect in the carboxylation reaction

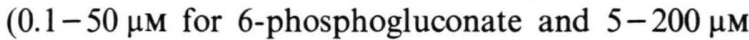
for fructose 1,6-bisphosphate), because it is apparent that these agents form kinetically stable complexes with the enzyme [3]. Our spectrophotometrical binding studies demonstrate that PLP binding is affected not at all by these sugar phosphates under these conditions.

A decrease of the aldimine formation between the carboxylase and PLP, however, is observed at higher concentrations of 6-phosphogluconate and fructose 
1,6-bisphosphate, where these agents inhibit $\mathrm{CO}_{2}$ fixation by competition with $\mathrm{RuP}_{2}$ at the reaction centers of the enzyme [3,7]. These results imply a competition between PLP and these sugar phosphates at the catalytical sites of the carboxylase. This interpretation is supported by protection experiments.

The substrate $\mathrm{RuP}_{2}$ functions as an effective protector against PLP inhibition both in the presence of $10 \mathrm{mM} \mathrm{MgCl}_{2}$ and without $\mathrm{Mg}^{2+}$. In the presence of $\mathrm{Mg}^{2+}$ protection is found at essentially higher $\mathrm{RuP}_{2}$ concentrations than in the absence of $\mathrm{Mg}^{2+}$. These protection experiments are in accordance with the effect of $\mathrm{RuP}_{2}$ on PLP binding, as measured spectrophotometrically. A decrease of the aldimine formation by preincubation of the enzyme with $\mathrm{RuP}_{2}$ is observed in the presence of $10 \mathrm{mM} \mathrm{MgCl}{ }_{2}$ as well as without $\mathrm{Mg}^{2+}$ in similar ranges of the $\mathrm{RuP}_{2}$ concentration, as measured previously in the functional studies. These results indicate two binding processes for the substrate $\mathrm{RuP}_{2}$ with different requirement for $\mathrm{Mg}^{2+}$. This is also apparent from other effects which will be presented in a forthcoming publication. These results are consistent with the conclusions of Whitman and Tabita [11] that PLP acts at the $\mathrm{RuP}_{2}$ binding site of the catalytical center, as demonstrated for the Rhodospirillum rubrum enzyme. In contrast to the results of Paech et al. [9] and Whitman et al. [11] we found that 6-phosphogluconate also functions as an efficient protector against PLP deactivation of the carboxylase. In this case protection occurs only in the presence of $\mathrm{Mg}^{2+}$. This again

[1] D. K. Chu and J. A. Bassham, Plant Physiol. 52, 373-379 (1973).

[2] D. K. Chu and J. A. Bassham, Plant Physiol. 54, 556-559 (1974).

[3] D. K. Chu and J. A. Bassham, Plant Physiol. 55, 720-726 (1975).

[4] B. B. Buchanan and P. Schuermann, J. Biol. Chem. 248, 4956-4964 (1973).

[5] F. J. Ryan and N. E. Tolbert, J. Biol. Chem. 250, 4234-4238 (1975).

[6] R. Chollet and L. L. Anderson, Arch. Biochem. Biophys. 176, 344-351 (1976).

[7] J. Vater and J. Salnikow, Arch. Biochem. Biophys. 194, 190-197 (1979). proofs the $\mathrm{Mg}^{2+}$ dependence of effector binding. The protection effect is observed at 6-phosphogluconate concentrations between $100 \mu \mathrm{M}$ and a few mM characteristic for the 6-phosphogluconate binding to the reaction centers of the carboxylase $[3,7]$.

The results of this paper imply a competition between PLP with $\mathrm{RuP}_{2}$ and regulatory sugar phosphates at the reaction centers of the spinach carboxylase. From our experiments it follows that PLP does not interfere directly with the allosteric sites of the enzyme. PLP binding at the catalytical sites obviously induces a modification of the effector binding at the regulatory sites. This conclusion points to a difference in the requirement for or the reactivity of functional amino groups for the binding of 6-phosphogluconate and fructose 1,6-bisphosphate at the catalytical and regulatory centers of RuBP carboxylases/oxygenases.

To what extent reactive amino groups for the binding of $\mathrm{CO}_{2}$ are involved in these processes, as suggested by Paech et al. [10], must be clarified by a further analysis of PLP inhibition and substrate binding. Such experiments as well as a further characterization of the effector binding sites of the $\mathrm{RuP}_{2}$ carboxylase/oxygenase are in progress.

\section{Acknowledgements}

This work is supported by grant Sa 267/2 from the Deutsche Forschungsgemeinschaft.

The authors are indebted to Mrs. B. Lange, Mrs. S. Gerhardt and Mrs. B. Kablitz for their excellent technical assistance.

[8] W. B. Whitman and F. R. Tabita, Biochem. Biophys. Res. Commun. 71, 1034-1039 (1976).

[9] C. Paech, F. J. Ryan, and N. E. Tolbert, Arch. Biochem. Biophys. 179, 279-288 (1977).

[10] C. Peach and N. E. Tolbert, J. Biol. Chem. 253, 7864-7873 (1978).

[11] W. B. Whitman and F. R. Tabita, Biochemistry 17, 1282-1287 (1978).

[12] J. Vater, J. Salnikow, and H. Kleinkauf, Biochem. Biophys. Res. Commun. 74, 1618-1625 (1977).

[13] H. Scharnow, Diplomarbeit, Technische Universität Berlin 1977.

[14] N. B. Whitman, C. Colletti, and F. R. Tabita, FEBS Letters 101, 249-252 (1979). 